\title{
Environmental News
}

\section{R.W. Raiswell}

Minerals and the Environment. Editor C.G. Down. 4/yr. (Science and Technology Letters, Kew, Surrey, UK.) £46. Environmental Technology Letters. Editors R.M. Harrison and J.N. Lester. 12/yr. (Science and Technology Letters, Kew, Surrey, UK.) £63.50. Environmental Pollution, Series B: Chemical and Physical. Editor K. Mellanby. $8 / \mathrm{yr}$ in 2 vols. (Applied Science, Barking, UK.) $£ 86$. Environment International. Editor-inchief A.A. Moghissi. $12 / \mathrm{yr}$ in 2 vols. (Pergamon.) \$160.

JOURNALS, like organisms, occupy niches. In this respect concepts borrowed from ecology provide an appropriate framework to consider the newly introduced environmental periodicals and the related questions of their usefulness and viability. The four journals considered here have all been introduced since April 1979, and between them cover most aspects of environmental pollution and its investigation.

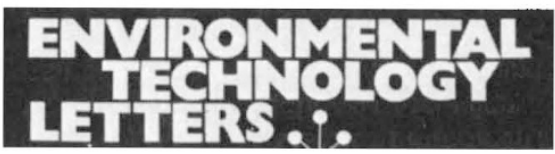

It is a feature of maturing ecosystems that the number of niches increases and their nature changes from "generalist" to "specialist". Similarly with journals: the immaturity of environmental studies is expressed in the generalist nature of three of the new journals, with only Minerals and the Environment (ME) being unashamedly specialist. In part, the growth of generalist journals rightly results from the interdisciplinary nature of environmental problems, but further competition inevitably raises questions of long-term viability. A brief survey of Current Contents Part C (including the environmental sciences) suggests that there are already a dozen or so generalist environmental journals (for example The Science of the Total Environment, Environmental Science and Technology, Chemosphere) which deal with more than one of the three physical states of matter from viewpoints which are not exclusively scientific. There are in addition still more specialist journals. In fact these four new journals deserve to succeed, although for diverse reasons.

ME is aimed at those who are professionally concerned with the identification, evaluation and amelioration of the environmental impact of mining. It is intended to cover resource issues, mineral economics, pollution, blasting problems, reclamation, subsidence, waste utilization, legislation, control and policy. The journal includes research papers, technical notes, reviews, conference reports and editorial. Certainly, it appears to fill a useful niche by bringing together a selection of articles which would otherwise appear in diverse journals. Given the growth and importance of the extractive industries and the increasing environmental constraints being placed upon them, it seems probable that the journal will be successful. The quality of production is high and the scope of the early issues appears to correspond with the editorial aims.

Environmental Technology Letters (ETL) is rather more generalist, being aimed at the field of environmental technology and covering sanitary and environmental engineering, air and water chemistry and pollution, solid waste management and industrial hygiene. The journal aims to offer publication within two months, an objective which is generally achieved. The quality of production (from camera-ready copy) is reasonably good and there is some improvement in later issues, although diagrams sometimes lack clarity and further uniformity in presentation could be achieved with specific instructions to authors in respect of form of sub-headings, presentation of tables and diagram captions. Certainly these are details, but ones which influence the reader's perception of the professional standing of a journal and which may ultimately be reflected in the quality of the scientific contributions. Rapid publication is unfortunately not combined with low costs, but despite these disadvantages ETL has a reasonably specific niche and will have a useful role as long as it can continue to attract contributions of at least average quality.

The appearance of Environmental Pollution, Series B: Chemical and Physical results from re-structuring the Environmental Pollution journal into a Series A, devoted mainly to the biological side of pollution, and introducing a complementary Series B for the chemical and physical aspects. The Series B journal still emphasizes the ecological aspects of chemical and physical pollution, including pollutant distribution, measurement techniques and international, political, economic, social, medical and managerial implications. Doubts about the viability of another generalist journal are assuaged in this case by the probability that the wellestablished Series A and newer Series B will mutually support each other. This seems to be confirmed to the extent that the Series B began with a quarterly appearance through 1980 , but now appears more frequently. The format is a typical one of research papers, review articles, short communications, book reviews and conference reports. Whilst the quality of production and scientific content are both good, the book reviews are too brief even to be indicative and the absence of submission dates on the manuscripts is regrettable.
Perhaps the most ambitious of the new journals is Environment International (EI), both in the quality of production and in its aim to present a forum for the discussion of environmental issues by involved parties, whether decision makers, scientists or engineers, as well as by the entire scientific community. The journal offers editorial comment, research articles and book reviews; some early issues are

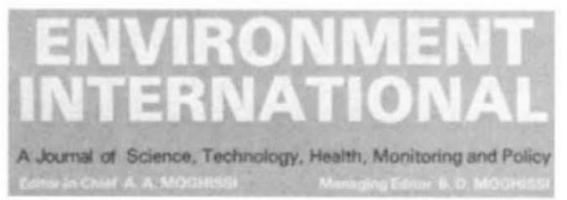

devoted to symposia or are thematic. Few other generalist journals have adopted such an authoritative stance and EI will ultimately be judged on the extent to which it can be relied upon for accurate, evenhanded treatment of a variety of complex issues. At present the quality of scientific contributions is high, but the editorial aim of involving individuals with widely differing professional backgrounds would be notably advanced by a more regular appearance of review articles, commissioned to cover a range of environmental issues.

R.W. Raiswell is a Lecturer in the School of Environmental Sciences at the University of East Anglia.

\section{... and Views}

\section{Lynton K. Caldwell}

Environmental Impact Assessment Review. Senior editor L.E. Susskind, editor Rebecca R. Packard. 4/yr. (Plenum.) \$35 US, \$41 elsewhere (personal); $\$ 70$ US, $\$ 79$ elsewhere (institutional). The Environmental Professional. Editor-in-chief R. Rajagopal. 4/yr. (Pergamon.) £78.04 UK, \$160 US.

Environmental Impact Assessment Review is described by its senior editor as a "publication for planners, engineers, scientists, and administrators involved in the practice of impact assessment"'. The Review was an outcome of a Rockefellerassisted project at MIT which supported a periodical of irregular issue called the $E I A$ Review. To date, issues of this successor normally contain statements of editorial policy and public commentaries, four to five feature articles, and short articles or information pieces classified under the heading of "departments" - for example, Generating Alternative Policies, Programs, and Designs; Impacts on the Natural Environment; Social Impact Assessment; Presenting Technical Information; and NEPA: Theory and Practical Application. 